Jurnal Mahasiswa BK An-Nur : Berbeda, Bermakna, Mulia

Volume 7 Nomor 1 Tahun 2021

Tersedia Online: https://ojs.uniska-bjm.ac.id/index.php/AN-NUR

p-ISSN. 2460-9722 | e-ISSN. 2622-8297

\title{
PENGEMBANGAN MEDIA PERMAINAN KARTU UNO UNTUK MENINGKATKAN KECERDASAN EMOSIONAL SISWA SMA
}

\author{
Silvia Septyani ${ }^{1}$, Zainal Fauzi ${ }^{2}$, Rudi Haryadi ${ }^{3}$ \\ ${ }^{1,2,3}$ FKIP, Universitas Islam Kalimantan Muhammad Arsyad Al-Banjari, Banjarmasin \\ E-mail: silviaseptyani17@gmail.com
}

\begin{abstract}
ABSTRAK
Masih banyak ketidakmampuan siswa dalam pengedalian emosi ini sejalan dengan hasil dari studi pendahuluan yang membuktikan siswa memiliki kecerdasan emosional yang rendah di SMA Kecamatan Karang Intan. Upaya guru BK di lapangan dalam meningkatkan kecerdasan emosional siswa selama ini hanya sebatas pemberian informasi menggunakan media power point, dimana media yang digunakan tersebut kurang efektif untuk meningkatkan kecerdasan emosional siswa. Penelitian ini bertujuan untuk menghasilkan sebuah produk berupa media permainan kartu UNO untuk meningkatkan kecerdasan emosional siswa dan untuk mengetahui kelayakannya. Metode yang digunakan dalam penilitian ini adalah menggunakan RnD model PPE yang dikembangkan oleh Richey dan Klein. Hasil penelitian ini telah menghasilkan media permainan Kartu UNO untuk meningkatkan kecerdasan emosional yang layak berdasarkan uji validasi materi dan media. Hasil uji validasi yang di dapat dari 3 ahli memperoleh hasil rata-rata 4,2 dengan kriteria "sangat baik" dan dari 2 praktisi memperoleh hasil rata-rata 4,5 dengan kriteria "sangat baik" dengan catatan sedikit revisi atau perbaikan dalam model yang dikembangkan. Saran selajutnya model ini masih memerlukan ujicoba di lapangan guna mengetahui efektifitas dan efisiensinya.
\end{abstract}

Kata Kunci: Permainan, Media Kartu UNO, Kecerdasan Emosional

\begin{abstract}
There are still many inability of students in controlling emotions in line with the results of a preliminary study that proves students have low emotional intelligence in Karang Intan District High School. The efforts of BK teachers in the field in increasing students 'emotional intelligence have so far been limited to providing information using power point media, where the media used are less effective at increasing students' emotional intelligence. This study aims to produce a product in the form of UNO card game media to increase students' emotional intelligence and to determine their worthiness. The method used in this research is to use the PPE RnD model developed by Richey and Klein. The results of this study have produced UNO Card playing media to increase appropriate emotional intelligence based on material and media validation tests. Validation test results obtained from 3 experts obtained an average of 4.2 with "very good" criteria and from 2 practitioners obtained an average of 4.5 with "very good" criteria with a slight revision or improvement in the model. developed. Suggestions hereafter that this model still needs field trials to find out its effectiveness and efficiency.
\end{abstract}

Keywords: Games, UNO Card Media, Emotional Intelligence

Dipublikasikan Oleh :

UPT Publikasi dan Pengelolaan Jurnal

Universitas Islam Kalimantan Muhammad Arsyad Al-Banjari Banjarmasin 
Silvia Septyani. Zainal Fauzi, Rudi Haryadi Jurnal Mahasiswa BK An-Nur : Berbeda, Bermakna, Mulia Volume 7 Nomor 1 Tahun 2021

Tersedia Online: https://ojs.uniska-bjm.ac.id/index.php/AN-NUR p-ISSN. 2460-9722 | e-ISSN. 2622-8297

\section{PENDAHULUAN}

Daniel Goleman (2016) menganggap emosi merujuk pada suatu perasaan dan pikiran yang khas, suatu keadaan biologis dan psikologis dan serangkaian kecenderungan untuk berperilaku atau bertindak. Emosi merupakan reaksi terhadap rangsangan dari luar dan dalam diri individu, sebagai contoh emosi gembira mendorong perubahan suasana hati seseorang, sehingga secara fisiologi terlihat tertawa, sedangkan secara biologisnya menimbulkan ketenangan dan menghambat perasaan negatif, contoh lain emosi sedih mendorong seseorang berperilaku menangis.

Beberapa tokoh mengemukakan tentang macam-macam emosi, antara lain Descrates, JB Watson dan Daniel Goleman. Menurut Descrates, emosi terbagi atas : Desire (hasrat), Hate (benci), Sorrow (sedih/duka), Wonder (heran), Love (cinta) dan Joy (kegembiraan), sedangkan JB Watson mengemukakan tiga macam emosi, yaitu : Fear (ketakutan), Rage (kemarahan), Love (cinta). Daniel Goleman (2016) mengemukakan beberapa macam emosi yang tidak berbeda jauh dengan kedua tokoh di atas, yaitu amarah, kesedihan, rasa takut, kenikmatan, cinta, terkejut, jengkel, dan malu. Mayer (dalam Goleman, 2016:63) menyebutkan bahwa orang cenderung menganut gaya-gaya khas dalam menangani dan mengatasi emosi mereka, yaitu : sadar diri, tenggelam dalam permasalahan, dan pasrah. Melihat keadaan itu maka penting bagi setiap individu memiliki kecerdasan emosional agar menjadikan hidup lebih bermakna dan tidak menjadikan hidup yang di jalani menjadi sia-sia.

Kecerdasan emosi merupakan cerminan dari perilaku yang muncul, sikap etik dasar dalam kehidupan berasal dari kemampuan emosional yang melandasinya. Walaupun emosi marah yang terjadi pada manusia atau remaja adalah hal wajar tetapi jika emosi negatif tersebut tidak tekendali maka akan menimbulkan permasalahan lainnya, dan kenyataannya remaja lebih sering meluapkan emosi marahnya atau emosi negatif karena kurangnya pengendalian emosi. Karena banyaknya muncul permasalahan dalam pengedalian emosi, hal ini sejalan dengan hasil dari studi pendahuluan menggunakan angket DCM (Daftar Cek Masalah) dan pendapat guru BK SMA Negeri 1 Karang Intan terdapat sejumlah siswa yang memliki pengendalian emosi rendah. Menurut hasil wawancara (tidak terstuktur) di SMA Karang Intan upaya guru BK di lapangan dalam meningkatkan kecerdasan emosional siswa selama ini hanya sebatas pemberian informasi melalui bimbingan klasikal dan bimbingan kelompok dengan metode ceramah atau menggunakan media power point.

Hasil penelitan terdahulu oleh Utomo, Yusmansyah \& Widiastuti (2018) membuktikan bahwa penggunaan layanan bimbingan kelompok teknik permainan efektif untuk meningkatkan kemampuan regulasi emosi siswa dan pada penelitian Erwin \& Wahidahtun (2018) tentang efektivitas layanan bimbingan kelompok untuk meningkatkan kecerdasan emosionasiswa kelas XI IPA SMA IP Yakin Jakarta menunjukan perhitungan data angket untuk pre-test dan post-test diperoleh skor pre-test kelompok eksperimen (O1) sebesar 3619 dengan rata-rata skor yang didapat per siswa adalah 139,2 kemuadian setelah diberikan treatment diperoleh hasil posttest sebesar 3952 dengan rata-rata skor per siswa sebesar 152. Penelitian Ulandari \& Juliawati

\section{Dipublikasikan Oleh :}


Silvia Septyani. Zainal Fauzi, Rudi Haryadi Jurnal Mahasiswa BK An-Nur : Berbeda, Bermakna, Mulia Volume 7 Nomor 1 Tahun 2021

Tersedia Online: https://ojs.uniska-bjm.ac.id/index.php/AN-NUR p-ISSN. 2460-9722 | e-ISSN. 2622-8297

(2019) tentang pemanfaatan layanan bimbingan kelompok untuk meningkatkan kecerdasan emosi siswa juga menunjukan bahwa terdapat pengaruh yang signifikan dengan skor pretest kelompk rata-rata 149,5 dan skor rata-rata postest 193,3. Jannah \& Mahidin (2019) juga melakukan penelitian tentang pengaruh layanan bimbingan kelompok terhadap kecerdasan emosional siswa di SMA Muhammadiyah-2 Medan T.A 2016/2017 menunjukan bahwa penelitian tersebut berpengaruh.

Berdasarkan pemasalahan yang muncul peneliti tertarik untuk melakukan sebuah pengembangan media permainan kartu UNO untuk meningkatkan kecerdasan emosional siswa SMA di Kecamatan Karang Intan. Penelitian ini akan menggunakan permainan kartu UNO sebagai media untuk meningkatkan kecerdasan emosional siswa karena kartu UNO termasuk permainan yang populer di kalangan remaja dibuktikan dengan banyaknya penelitian tentang kartu UNO yang diterapkan pada siswa SMP atau SMA yaitu pada penelitian Agustin (2018) tentang pengembangan media pembelajaran kartu uno pada materi bank untuk siswa kelas $\mathrm{X}$ IIS MAN 2 Lamongan, penelitian Witantyo (2017) tentang pengembangan media pembelajaran kartu uno akuntansi untuk meningkatkan motivasi belajar siswa kelas X Akuntansi 4 SMK YPKK 2 Sleman dan penelitian Samsusilowari (2016) tentang pengembangan permainan kartu uno sebagai alat evaluasi pembelajaran akuntansi di SMK YPKK 2 Sleman.

Pada penelitian Estiani, Widiyatmoko \& Sarwi (2015) tentang pengembangan media permainan kartu UNO untuk meningkatkan pemahaman konsep dan karakter siswa kelas VIII tema optik, hasil penelitiannya menunjukan media permainan kartu UNO efektif dilakasanakan dikelas yang di tunjukan dengan ketuntasan klasikal hasil belajar mencapai 79,31\% yang awalnya tidak terdapat siswa yang melampaui batas ketuntasan (KKM), dan hasil didapatkan dari karakter rasa ingin tahu siswa mendapatkan nilai dari pertemuan ke-1 56,32\% menjadi $88,51 \%$ pada pertemuan ke-4, sehingga media permainan kartu UNO dapat mengembangakan karakter siswa. Kartu UNO juga dianggap mampu untuk meningkatkan kecerdasan emosional karena dalam penelitian Adhim (2012) ada hubungan pendidikan karakter terhadap kecerdasan emosional pada mahasiswa fakultas ekonomi universitas kanjuruhan malang terdapat hubungan yang signifikan dengan nilai koefisien kolerasi (r) sebesar 0,582 .

Permainan kartu UNO juga telah dikembangkan pada layanan bimbingan konseling bidang karir oleh Aminah (2018) yang membuktikan bahwa permainan kartu UNO karier ini layak digunakan sebagai media perencanaan karier siswa setelah melalui tahap validasi ahli materi, validasi media dan uji coba kepada siswa. Penelitian Aminah (2018) tersebut dibuktikan kembali oleh Ariska (2019) melalui uji coba eksperimen yang menunjukkan bahwa bimbingan kelompok menggunakan media permainan kartu UNO efektif untuk meningkatkan perencanaan karier siswa. Pada penelitian Hanani (2016) juga membahas tentang pengembangan kartu karir sebagai media dalam bimbingan karir siswa SD Negeri Samirono dengan hasil uji ahli materi yang meliputi 19 item pernyataan terkait dengan kelayakan isi, kebahasaan, penyajian, dan tujuan bimbingan karir, maka diperoleh rata-rata skor 1 (1 artinya sesuai, 0

Dipublikasikan Oleh :

UPT Publikasi dan Pengelolaan Jurnal

Universitas Islam Kalimantan Muhammad Arsyad Al-Banjari Banjarmasin 
Silvia Septyani. Zainal Fauzi, Rudi Haryadi Jurnal Mahasiswa BK An-Nur : Berbeda, Bermakna, Mulia Volume 7 Nomor 1 Tahun 2021

Tersedia Online: https://ojs.uniska-bjm.ac.id/index.php/AN-NUR p-ISSN. 2460-9722 | e-ISSN. 2622-8297

artinya tidak sesuai) dengan kategori baik dan dinyatakan telah layak untuk digunakan.

Dimana perencanaan karir berhubungan dengan kecerdasam emosional yang dibuktikan oleh penelitian Drastiana (2016) hasil penelitiannya menunjukkan terdapat hubungan positif yang sangat signifikan antara kecerdasan emosi dengan pengambilan keputusan karir, dengan nilai $r$ sebesar 0,522 dan nilai $\mathrm{p}=0,01 \quad(0,000<0,01)$ dan pada penelitian Lestari \& Rahardjo (2013) juga membuktikan terdapat kolerasi positf yang signifikan antara kecerdasan emosional dengan kematangan karir, maka dari itu pengembangan media permainan kartu UNO juga dapat digunakan untuk menigkatkan kecerdasan emosional.

Pada penelitian sebelumnya banyak menggunakan permainan kartu baik itu UNO ataupun jenis kartu yang lain dalam mata pelajaran dan juga pada layanan bimbingan konseling terutama bidang karir yang digunakan melalui layanan bimbingan kelompok dimana penggunaan permainan kartu UNO untuk meningkatkan kecerdasan emosional belum pernah digunakan. Letak perbedaan pengembangan media permainan kartu UNO yang sudah ada dengan yang akan peneliti kembangkan adalah media permainan kartu UNO yang dikengembangan pada mata pelajaran berisikan soal-soal yang berkaitan dengan mata pelajaran tersebut yang harus di jawab siswa layaknya kuis, kemudian pada media permainan kartu UNO yang dikembangan oleh Aminah (2018) kartu UNO berisikan informasi bidang pekerjaan, jenis-jenis pekerjaan yang disesuaikan dengan era revolusi industri 4.0 serta beberapa kartu pertanyaan berkaitan dengan perencanaan karier siswa pada jenjang SMP sedangkan pada pengembangan media permainan kartu UNO pada penelitian ini pertanyaan yang digunakan dalam kartu tidak hanya layaknya kuis tetapi sebuah kasus yang harus dipecahkan dimana kasus tersebut disesuaikan dengan permasalahan yang sering terjadi disekolah dan juga tidak hanya berisikan kasus/soal tetapi juga terdapat punishment atau reward sebagai selingan.

Dipublikasikan Oleh :

UPT Publikasi dan Pengelolaan Jurnal

Universitas Islam Kalimantan Muhammad Arsyad Al-Banjari Banjarmasin 
Silvia Septyani. Zainal Fauzi, Rudi Haryadi Jurnal Mahasiswa BK An-Nur : Berbeda, Bermakna, Mulia Volume 7 Nomor 1 Tahun 2021

Tersedia Online: https://ojs.uniska-bjm.ac.id/index.php/AN-NUR p-ISSN. 2460-9722 | e-ISSN. 2622-8297

Pengembangan media permainan kartu UNO ini seperti permainan yang di kembangkan oleh Bekesas \& Berimbau (2018) dimana dalam kartu di selipkan sebuah kasus atau cerita yang menyangkut topik permasalahan dan pemain akan menceritakan dan memberikan solusi atas kasus yang diberikan pemimpin kelompok lalu jawaban dari pemain di bahas bersama anggota kelompok yang lain, setiap warna kartu UNO akan di sesuaikan dengan teori Goleman (2016) yang menyangkut kecerdasan emosional, dan setiap pemain yang mengeluarkan skip card pemain selanjutnya akan mendapatkan punishment atau reward seperti penelitian Chen (2017) tentang efektivitas pengunaan permainan kartu hadiah, tetapi dalam penelitian Chen (2017) kartu pendidikan tersebut yang menjadi rewardnya, sedangkan dalam penelitian yang dikembangkan peneliti reward diberikan oleh anggota kelompok dan pemimpin kelompok.

\section{METODE}

Penelitian dan pengembangan yang dilakukan pada penelitian ini berdasarkan pada model PPE (planning, production, and evaluation) yang dikembangkan oleh Richey dan Klein. Richey dan Klein menyatakan “ The focus of research and development design can be on front-end analysis planning, production and evaluation (PPE)".

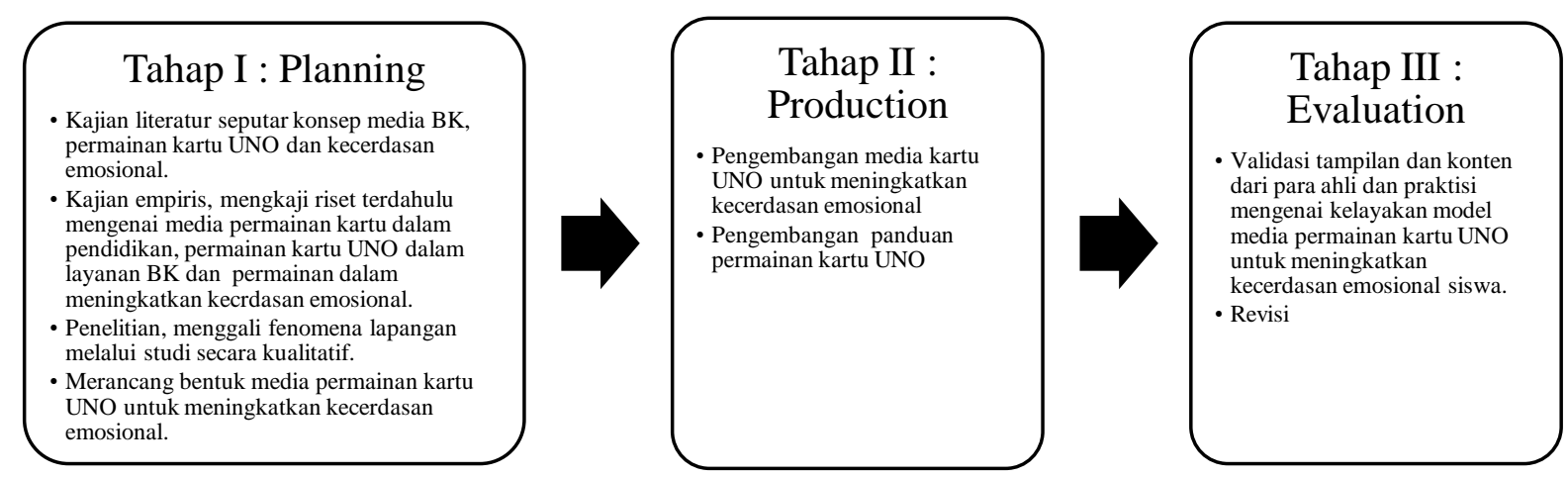

Gambar 1. Prosedur pengembangan model media permainan kartu UNO.

Sumber data dalam penelitian ini yaitu para ahli bidang kecerdasan emosional/pengendalian emosi, ahli media BK dan ahli pendekatan kreatif dalam BK, setiap bidang dibutuhkan satu orang ahli untuk memvalidasi model. Selain para ahli sumber data dalam penelitian ini juga menggunakan hasil validasi dari dua orang praktisi. Dalam penelitian ini, digunakan beberapa teknik dan instrumen pengumpulan data. Teknik dan instrumen pengumpulan data dimaksudkan untuk mengumpulkan data

\section{Dipublikasikan Oleh :}

\section{UPT Publikasi dan Pengelolaan Jurnal}

Universitas Islam Kalimantan Muhammad Arsyad Al-Banjari Banjarmasin 
yang dapat digunakan sebagai dasar untuk menetapkan tingkat kelayakan dan/atau daya tarik dari produk yang dihasilkan. Secara umum, jenis data dalam penelitian ini yaitu data kualitatif dengan wawancara, studi dokumentasi dan kuesioner delphi untuk mengumpulkan data validasi ahli dan praktisi.

Teknik analisis dalam penelitian ini menggunakan analisis kualitatif dan analisis delphi. Analisis kualitatif yang digunakan yaitu teknik yang dikemukakan oleh Miles, Huberman, dan Saldana (2014) dalam teknik ini, analisis data kualitatif melalui tiga tahapan utama, meliputi: (1) kondensasi data; (2) display data; dan (3) menggambarkan kesimpulan/verifikasi. Sedangkan analisis delphi dilakukan terhadap hasil kuesioner delphi yaitu dengan mengelompokkan informasi-informasi data kualitatif berupa skor penilaian, tanggapan, masukan, serta saran dari uji ahli dan praktisi. Selanjutnya hasil analisis data kualitatif tersebut dijadikan pertimbangan untuk melakukan revisi produk.

\section{HASIL DAN PEMBAHASAN}

Hasil pelaksanaan keseluruhan prosedur pengembangan dalam penelitian ini pada tahap perencanaan pengembangan media permainan kartu UNO didapatkan hasil dari studi literatur, kajian empiris, pengumpulan data melalui angket DCM, wawancara dan studi dokumentasi. Wawancara untuk mengungkap kebutuhan lapangan akan pengembangan media permainan kartu UNO dilakukan oleh peneliti kepada dua orang guru BK yang bertugas selaku sumber data di SMA Kecamatan Karang Intan. Berdasarkan kedua hasil wawancara dengan sumber data yang berbeda tersebut dapat diketahui beberapa hal tentang perencanaan pengembangan model media permainan kartu UNO untuk meningkatkan kecerdasan emosional siswa SMA di Kecamatan Karang Intan.

Dengan demikian, data yang ditemukan secara umum dari hasil wawancara adalah (1) Kartu UNO dapat dimanfaatkan dan berpotensi untuk pengembangan media BK di SMA Kecamatan Karang Intan, (2) Siswa di SMA Kecamatan Karang Intan dominan suka bermain baik di luar dan saat jam pelajaran, (3) Harapan guru BK media kartu UNO dapat meningkatkan kecerdasan emosional siswa secara signifikan dan dapat digunakan oleh semua guru BK, (4) Punishment dan reward yang diberikan diluar materi kecerdasan emosional tetapi masih terkesan mendidik, reward dapat diberikan oleh anggota kelompok lain atau pemimpin kelompok, (5) Model media permainan kartu UNO disuguhkan dengan warna-warna cerah yaitu merah, kuning, hijau, biru dan ungu, (6) Dimasa depan siswa mampu bersosialisasi dengan baik untuk memasuki dunia baru, (7) Kendala dilapangan tidak dapat digunakan pada ruang terbuka karena dapat menimbulkan kesalahpahaman, (8) Materi disetting problem solving yaitu pemecahan kasus-kasus yang sering terjadi disekolah, (9) Mengetahui tujuan telah berhasil melalui pengukuran menggunakan skala kecerdasan emosional dan pemantauan langsung, (10) Hal yang diperlukan untuk mencapai sasaran yaitu melakukan tindak lanjut, (11) Ganjaran yang didapat siswa yaitu dapat mengendalikan emosinya,

\section{Dipublikasikan Oleh :}


mengelola emosionya agar terjalin hubungan yang baik antar siswa.

Berdasarkan hasil penggalian informasi dan studi literatur mengenai rencana pengembangan media permainan kartu UNO, peneliti menghasilkan model media permainan kartu UNO yang terdiri dari (1) Media Kartu UNO EQ dan (2) Buku panduan permainan kartu UNO. Pada tahap evaluasi dilakukan uji kelayakan yang dilakukan oleh 3 orang ahli dan 2 orang praktisi untuk divalidasi kontennya, maka diperoleh data sebagaimana dipaparkan pada tabel 4.2 yang menunjukkan skor penilaian kuantitatif yang dikategorikan berdasarkan kriteria Sangat Baik (4,00-5,00), Baik (3,003,99), Kurang Baik (2,00-2,99), dan Tidak Baik (1,00-1,99).

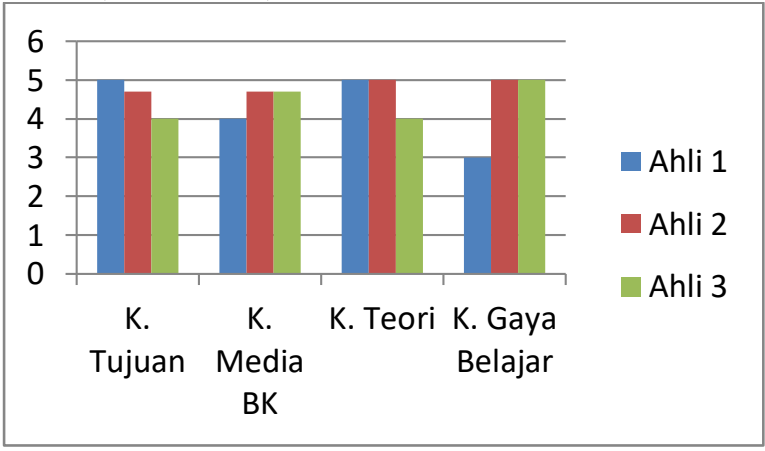

Gambar 2. Grafik hasil validasi para ahli.

Hasil validasi secara kuantitatif pada gambar 2 menunjukkan bahwa media permainan kartu UNO yang dikembangkan rata-rata memiliki tingkat kesesuaian tujuan, kesesuaian media dengan materi BK, kesesuaian dengan teori dan kesesuaian dengan gaya belajar siswa yang sangat baik. Hanya beberapa aspek seperti kesesuaian dengan karakteristik siswa dan aspek kesesuaian dengan kondisi lingkungan, fasilitas pendukung dan waktu penggunaan media permainan kartu UNO yang dinilai termasuk dalam kategori baik oleh para ahli. Walau demikian, secara umum model media permainan kartu UNO untuk meningkatkan kecerdasan emosional dinilai berada dalam kategori sangat baik oleh validator ahli $(X=$ $4,2)$, dan validator praktisi $(X=4,5)$. Dengan bebrapa masukan beberapa tema perbaikan yaitu (1) perlu adanya sedikit tambahan desain pada kartu UNO dengan memberikan sisipan foto/gambar. (2) Perlu adanya revisi font pada buku panduan dan tambahan untuk mencantumkan skor dalam menentukan kecerdasan EQ yang rendah (Interval), waktu yang diperlukan, keterangan batas usia pemain dalam permainan kartu UNO EQ dan biografi penulis. (3) Perlu adanya revisi pada lampiran panduan permainan yaitu RPL.

Pengembangan media kartu UNO ini hampir serupa dengan pengembangan media permainan kartu UNO lainnya seperti pengembangan media kartu UNO pada layanan BK bidang yang lain atau pada mata pelajaran (Aminah, 2018; Estiani, Widiyatmoko \& Sarwi, 2015; Hanani, 2016; Kusuma \& Pratiwi, 2016; Yanti \& Susanti, 2017; Witantyo, 2017; Agustin, 2018). Hanya saja tingkat kesulitan dan perbedaan pengembangan model ini terletak pada kasus yang dibahas, kasus yang dimuat dalam media kartu UNO ini diolah problem solving, kasus yang diangkatpun yang sering terjadi di lingkungan sekolah, dan model ini juga sudah sesuai dengan maksud dari produk yang mampu menjadi perantara penyampaian pesan bimbingan dan konseling yang dapat merangsang pikiran, perasaan, perhatian, dan kemauan peserta

\section{Dipublikasikan Oleh :}

\section{UPT Publikasi dan Pengelolaan Jurnal}

Universitas Islam Kalimantan Muhammad Arsyad Al-Banjari Banjarmasin 
didik/konseli untuk menangkap pesan dengan tepat. (Suryapranata (2016:73)

Model ini dalam pelaksanaannya, sangat mengedepankan proses berpikir rasional untuk mengurangi tekanan dan membekali keterampilan yang pada tujuan akhirnya memberikan dampak pada peningkatan kesejahteraan psikologis. Materi yang dimasukkan dalam model ini berkaitan dengan lima komponen yang ada dalam teori kecerdasan emosional Deniel Goleman (2016).

\section{PENUTUP}

Model media permainan kartu UNO untuk meningkatkan kecerdasan emosional siswa merupakan model hasil pengembangan yang terdiri dari komponen padu, yaitu: (1)Panduan permainan Kartu UNO EQ dan (2) Hasil uji validasi secara kuantitatif menunjukkan bahwa model ini secara umum dinilai berada dalam kategori sangat baik. Hanya beberapa aspek dinilai termasuk dalam kategoribaik oleh para ahli, utamanya pada kesesuaian dengan karakteristik siswa dan kesesuaian dengan kondisi lingkungan, fasilitas pendukung dan waktu yang tersedia.

Dalam melaksanakan layanan menggunakan media permainan kartu UNO $\mathrm{EQ}$, Guru BK perlu menambah wawasan dan meningkatkan keterampilan dalam halhal teknis seperti melaksanakan asesmen, bimbingan, edukasi, dan memberikan pemahaman kepada klien. Siswa diharapkan mampu berfikir kritis dalam pemecahan masalah yang diberikan guru BK melalui media permainan kartu UNO EQ dan melakukan pembahasan masalah secara mendalam. Bagi peneliti selanjutnya yang melakukan penelitian serupa dengan penelitian ini, perlu memperhatikan beberapa hal, seperti: (1) perlu menggunakan ukuran sampel yang lebih besar dalam mengukur tingkat kecerdasan emosional siswa SMA agar hasilnya dapat digeneralisasikan; (2) Model yang dikembangkan peneliti agar diuji coba lapangan terlebih dahulu untuk menguji keefektifan model; pengembangan lebih lanjut diperlukan untuk implementasi model pada populasi yang lebih luas.

\section{REFERENSI}

Adhim, F. (2012). Hubungan Pendidikan Karakter Terhadap Kecerdasan Emosional Pada Mahasiswa Fakultas Ekonomi Universitas Kanjuruhan Malang. Jurnal Inspirasi Pendidikan, 1(1). 29-38.

Aminah, S. (2018). Pengembangan alat permainan kartu uno career sebagai media perencanaan karir siswa di SMPN 1 pengasih. Jurnal Riset Mahasiswa Bimbingan Dan Konseling, 4(10), 650-658.

Ariska, D. (2019). Efektivitas bimbingan kelompok menggunakan media permainan kartu uno terhadap peningkatan perencanaan karier siswa smp. Jurnal Riset Mahasiswa Bimbingan Dan Konseling, 5(8), 556-566.

Bekesas, W.R., Berimbau, M., Mader, R.V., Pellerano, J \& Riegel, V (2018). CosmoCult Card Game: A Methodological Tool to Understand the Hybrid and Peripheral Cultural Consumption of Young People. Open Library of Humanities, 4(1). DOI: 10.16995/olh.167

\section{Dipublikasikan Oleh :}

\section{UPT Publikasi dan Pengelolaan Jurnal}

\section{Universitas Islam Kalimantan Muhammad Arsyad Al-Banjari Banjarmasin}


Chen, P., Kuo, R., Chang, M., \& Heh J-S (2017). The effectiveness of using ingame cards as reward. Research and Practice in Technology Enhanced Learning, $\quad 12: 15 . \quad$ DOI 10.1186/s41039-017-0054-8

Erwin, A., \& Wahidahtun, N. A. (2018). Efektivitas layanan bimbingan kelompok untuk meningkatkan kecerdasan emosional siswa kelas XI IPA SMA IP Yakin Jakarta tahun ajaran 2016/2017. Guidance, 15(02), 17-29.

Estiani, W., Widiyatmoko, A., \& Sarwi, S. (2015). Pengembangan Media Permainan Kartu Uno Untuk Meningkatkan Pemahaman Konsep dan Karakter Siswa Kelas VIII Tema Optik. Unnes Science Education Journal, 4(1). 711-719

Goleman, D (2016). Emotional Intelligence Kecerdasan Emosional Buku Menggemparkan Yang Mendefinisikan Ulang Apa Arti Cerdas Mengapa EI Lebih Penting Daripada IQ. Jakarta: PT Gramedia Pustaka Utama.

Jannah, N \& Mahidin (2019). Pengaruh layanan bimbingan kelompok terhadap kecerdasan emosional siswa di sma muhammadiyah-2 medan. $A l$ Mursyid: Jurnal Ikatan Alumni Bimbingan dan Konseling Islam (IKABKI), 1(1). 115-126.

Lestari, T.N \& Rahardjo, P ( 2013). Hubungan antara kecerdasan emosional dengan kematangan karir pada mahasiswa universitas muhamadiyah purwokerto yang sedang menempuh skripsi. Psycho Idea. 11 (2). DOI: 10.30595

Ulandari, Y., \& Juliawati, D. (2019). Pemanfaatan layanan bimbingan kelompok untuk meningkatkan kecerdasan emosi siswa. Indonesian Journal of Counseling and Development, 1(1), 1-8.

Utomo, E.T., Yusmansyah, Y., \& Widiastuti, R. (2018). Penggunaan Layanan Bimbingan Kelompok Teknik Permainan untuk Meningkatkan Kemampuan Regulasi Emosi Siswa. ALIBKIN (Jurnal Bimbingan Konseling), 6(3).

Yanti, R. A. E \& Susanti, Y. (2017). Aplikasi smart card game uno acounting sebagai alat evaluasi pembelajaran akuntansi. Jurnal Edukasi (Ekonomi, Pendidikan dan Akuntansi), 5(2). 131-136.

Dipublikasikan Oleh :

UPT Publikasi dan Pengelolaan Jurnal

Universitas Islam Kalimantan Muhammad Arsyad Al-Banjari Banjarmasin 